\title{
GERENCIAMENTO DO FLUXO DE INFORMAÇÃO COMO SUPORTE AO PROCESSO DE TOMADA DE DECISÃO
}

\author{
GESTIÓN DEL FLUJO DE INFORMACIÓN COMO APOYO EN EL \\ PROCESO DE TOMA DE DECISIONES: UNA REVISIÓN
}

\author{
Luciane Paula Vital - luciane.vital@ufpe.br \\ Docente da Universidade Federal de Pernambuco \\ Vivian Mengarda Floriani - vivifloriani@hotmail.com \\ Mestre em Ciência da Informação \\ Gregório Varvakis - grego@deps.ufsc.br \\ Doutor em Manufacturing Engineering. \\ Docente da Universidade Federal de Santa Catarina.
}

\begin{abstract}
Resumo
Objetiva mapear os modelos de fluxo de informação no processo de tomada de decisões considerando que a informação desempenha papel importante e imprescindível nas organizações, exigindo gerenciamento eficaz e esforços conjuntos dos seus membros. Destaca como requisito da gestão da informação, a importância do estabelecimento de processos, etapas ou fluxos sistematizados e estruturados, associado às pessoas responsáveis por sua condução, para que se obtenham os resultados almejados. Salienta que a investigação do fluxo informacional permite verificar e subsidiar o processo de tomada de decisões. Espera, com este trabalho, contribuir para a compreensão de que a informação exerce função básica no processo decisório em termos de aumento da qualidade e diminuição das incertezas.
\end{abstract}

\section{Palavras-chave}

Fluxo de informação. Tomada de decisão. Gestão da informação.

\section{INTRODUÇÃO}

A gestão da informação requer o estabelecimento de processos, etapas ou fluxos sistematizados e estruturados, associado às pessoas responsáveis por sua condução, Inf. Inf., Londrina, v. 15, n. 1, p. 85 - 103, jul./jun. 2010 
para que se obtenham os resultados almejados. Os fluxos de informação permitem o estabelecimento das etapas de obtenção, tratamento, armazenamento, distribuição, disseminação e uso da informação no contexto organizacional.

Uma das funções essenciais dos fluxos informacionais é dotar os gestores de subsídios imprescindíveis ao processo de tomada de decisões. Autores como Oliveira e Bertucci (2003, p. 8) consideram que "[...] o gerenciamento da informação tornou-se um instrumento estratégico necessário para controlar e auxiliar decisões, através de melhorias no fluxo da informação, do controle, análise e consolidação da informação para os usuários". É preciso reconhecer que as organizações que administrarem eficientemente a informação terão um recurso estratégico fundamental para a maximização da qualidade do processo decisório.

A literatura consultada é unânime em afirmar que a gestão da informação baseada no fluxo de informação é um recurso estratégico fundamental para o processo de tomada de decisão. O presente tem como objetivo apresentar os principais modelos de gestão da informação baseados no seu fluxo, com o propósito de qualificar o processo de tomada de decisão.

\section{GESTÃO DA INFORMAÇÃO BASEADA EM SEUS FLUXOS}

A gestão da informação requer o estabelecimento de processos, etapas sistematizadas, organizadas e estruturadas das quais os fluxos informacionais são responsáveis. Castells (2001, p. 501) possui uma visão a respeito de fluxos. Para ele

Fluxos não representam apenas um elemento da organização social: são a expressão dos processos que dominam nossa vida econômica, política e simbólica. [...] Por fluxos, entendo as seqüências intencionais, repetitivas e programáveis de intercâmbio e interação entre posições fisicamente desarticuladas, mantidas por atores sociais nas estruturas econômica, política e simbólica da sociedade.

O conceito de Castells é abrangente e se aplica aos diversos setores da sociedade. De uma forma mais específica e voltada para o contexto organizacional, McGee e Prusak (1994, p. 5) afirmam que "a criação, captação, organização, distribuição, interpretação e comercialização da informação são processos essenciais" para organizações preocupadas com a gestão da informação.

Evidencia-se que os fluxos informacionais podem ser observados sob dois critérios: o da tecnologia e o da Ciência da Informação $(\mathrm{Cl})$. Em relação à tecnologia, os fluxos permitem que o usuário acesse a informação da melhor forma, enquanto que a $\mathrm{Cl}$ 
interfere na qualificação da competência dos usuários, visando a assimilação dos conteúdos informacionais (BARRETO, 1999).

A informação deverá ser gerenciada através do estabelecimento de fluxos informacionais adequados à organização. Destarte, é imprescindível demonstrar os modelos de gestão da informação baseados nos fluxos informacionais e suas etapas. São analisados cinco modelos, sendo o primeiro de Smit e Barreto (2002), seguido por Lesca e Almeida (1994), o terceiro modelo de Davenport (1998), em seguida de McGee e Prusak (1994) e, finalmente de Beal (2004).

Smit e Barreto (2002) reconhecem três fluxos básicos de informação: o primeiro denominado 'interno' (captação, seleção, armazenamento e recuperação da informação), o segundo sendo a transformação da informação em conhecimento, e o último, a inscrição de informação, determinada pela consolidação da criação do autor. A figura 1 contextualiza os fluxos internos e os fluxos externos da informação.

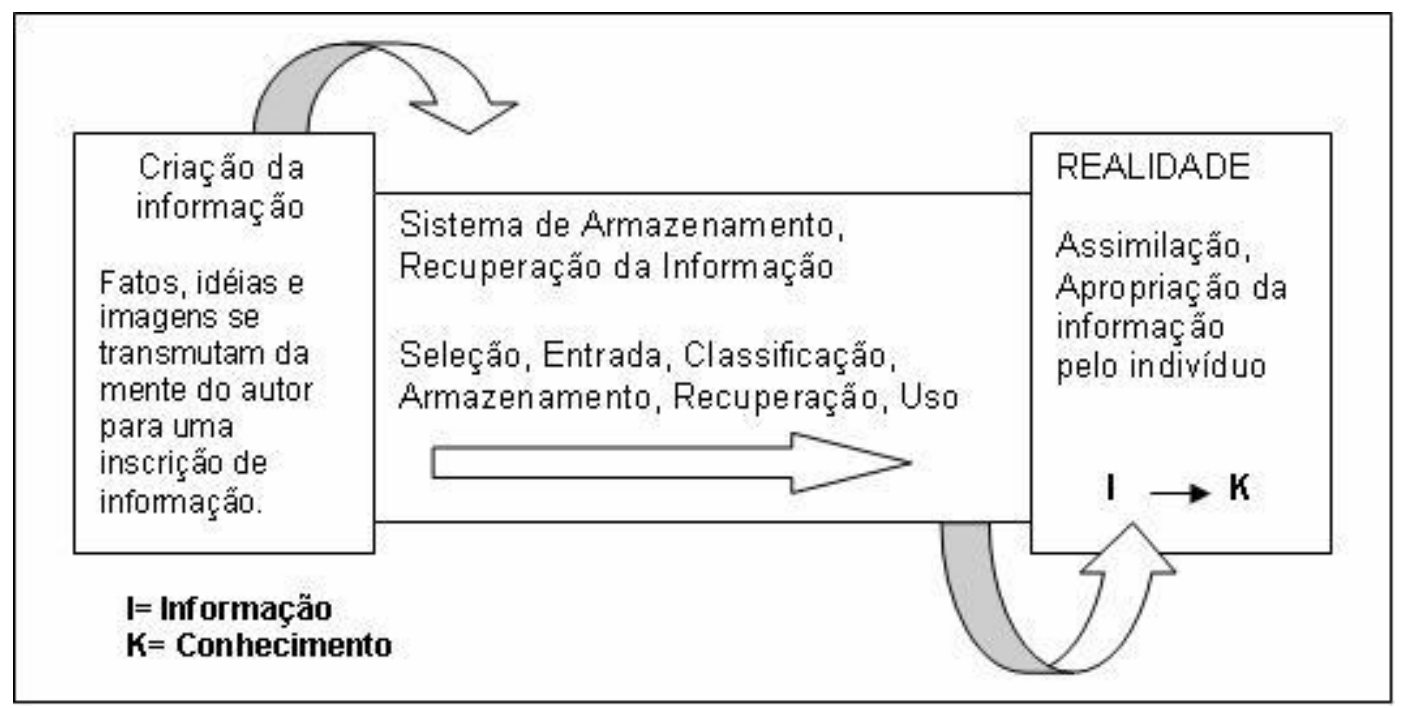

Figura 1 - Fluxos internos e externos de informação

Fonte - Smit e Barreto (2002)

Os autores consideram que os fluxos de informação permeiam em dois níveis: o interno e o externo. Segundo Smit e Barreto (2002, p. 16),

[...] os fluxos internos de informação, os quais de movimentam entre os elementos de um sistema que se orienta para sua organização e controle. [...] Os fluxos de informação de segundo nível são aqueles que acontecem nas extremidades do fluxo interno, de seleção, armazenamento e recuperação da informação. Os fluxos externos são aqueles que, por sua atuação, mostram a essência do fenômeno da transformação, um acontecimento raro e surpreendente entre a linguagem, suas inscrições e o conhecimento elaborado pelo receptor em sua realidade.

É importante acrescentar que o fluxo interno tem uma razão prática e de caráter organizacional, permitindo a tomada de decisões, ou seja, "é o mundo do gerenciamento e controle da informação" (SMIT; BARRETO, 2002, p. 16). 
O modelo de Lesca e Almeida (1994) apresenta o fluxo informacional de uma organização subdividido em três etapas, conforme a figura 2.

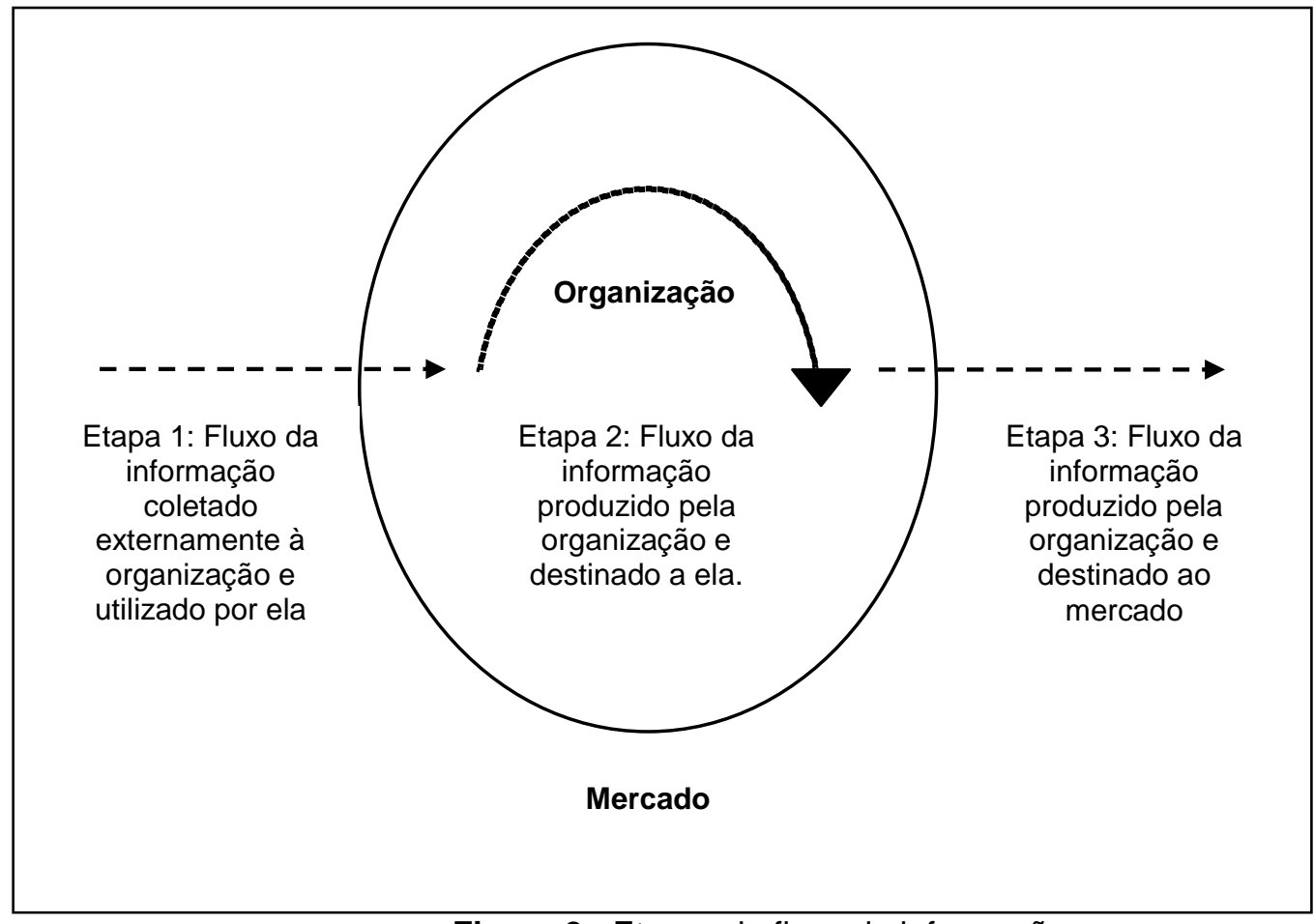

Figura 2 - Etapas do fluxo da informação

Fonte - Modificado de Lesca e Almeida (1994)

No modelo proposto os fluxos de informações são divididos em: a etapa do fluxo da informação advindo do ambiente externo e utilizado pela organização; a etapa do fluxo produzido e destinado à organização, ou seja, o fluxo no âmbito interno de informações, a etapa produzida pela organização e destinada ao mercado externo da organização (clientes, fornecedores, concorrentes).

Para Davenport (1998) há quatro passos que deverão ser seguidos (figura 3) para o efetivo gerenciamento da informação.

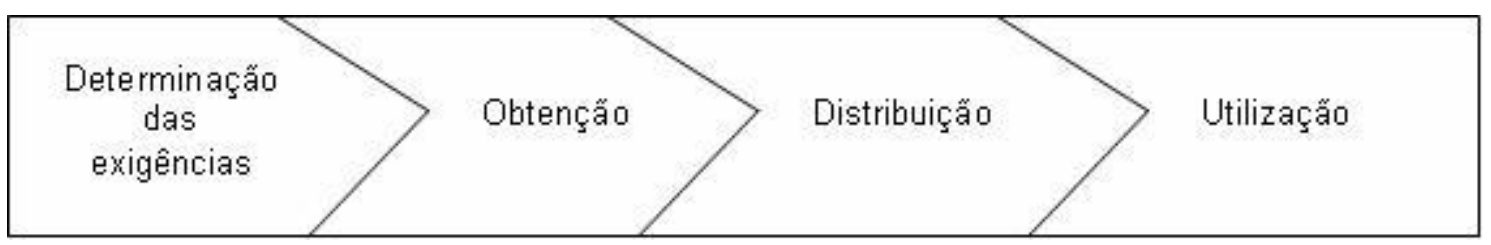

Figura 3 - O processo de gerenciamento da informação

Fonte - Davenport (1998)

O primeiro passo, que consiste em determinar as exigências da informação é, segundo Davenport (1998) problemático, pois demanda que as pessoas da organização percebam o ambiente que cerca as informações. Para o autor (1998, p. 178) "o passo um do processo parece assim a mais subjetiva das atividades, sendo impossível, para qualquer grupo externo à função, compreender de que tipo de informações um gerente realmente precisa". 
O segundo passo, denominado obtenção de informações, requer que se busquem de maneira ininterrupta as informações necessárias. Davenport (1998, p. 181) afirma que "[...] o processo mais eficaz é aquele que incorpora um sistema de aquisição contínua". A execução desse passo consiste nas seguintes atividades. A primeira diz respeito à exploração das informações, que deve ser realizada de maneira eficaz. A segunda atividade consiste em classificar as informações e a última atividade desse passo requer formatação e estruturação das informações, o que significa dizer que a organização deve gerenciar os documentos que dispõe e estruturá-los, para em seguida, formatá-los.

O terceiro passo do processo de gerenciamento da informação se refere à maneira pelas quais as informações são buscadas e divulgadas para os membros da organização. Davenport (1998, p. 189) assegura que "a distribuição envolve a ligação de gerentes e funcionários com as informações de que necessitam. Se os outros passos do processo estiverem funcionando, então a distribuição será mais efetiva [...]".

O último passo apontado por Davenport, denominado uso da informação diz respeito ao emprego da informação disponível aos usuários da organização. O autor afirma que (1998, p. 194) "a maneira como um funcionário procura, absorve e digere a informação antes de tomar uma decisão - ou se ele faz isso - depende pura e simplesmente dos meandros da mente humana". Ao finalizar a explanação sobre os passos para o gerenciamento da informação, Davenport (1998) chama a atenção para o fato de que o fluxo da informação deva ser gerenciado de modo ativo pelos gestores da organização.

O quarto modelo de gerenciamento da informação discutido é o de McGee; Prusak (1994) conforme a figura 4. A exemplo de Davenport (1998), os autores determinam quatro principais tarefas do processo de gerenciamento. Inicialmente tem-se a identificação de necessidades e requisitos de informação.

A primeira tarefa é, na opinião dos autores, a mais importante dentro do processo e, muitas vezes, negligenciada pelas organizações. McGee e Prusak (1994) entendem que há três aspectos essenciais nesta primeira etapa: (1) variedade necessária de informação para atuação no ambiente organizacional; (2) as pessoas não sabem o que não sabem, isto é, "profissionais da informação precisam ter conhecimento das fontes de informação disponíveis que podem ser valiosas para o cliente ou sua organização" (MCGEE; PRUSAK, 1994, p. 116); e (3) aquisição/coleta de informação que deverá contar com "um plano sistemático para adquirir a informação de sua origem ou coletá-la (eletrônica ou manualmente) dos que a desenvolvem internamente" (MCGEE; PRUSAK, 1994, p. 117). 


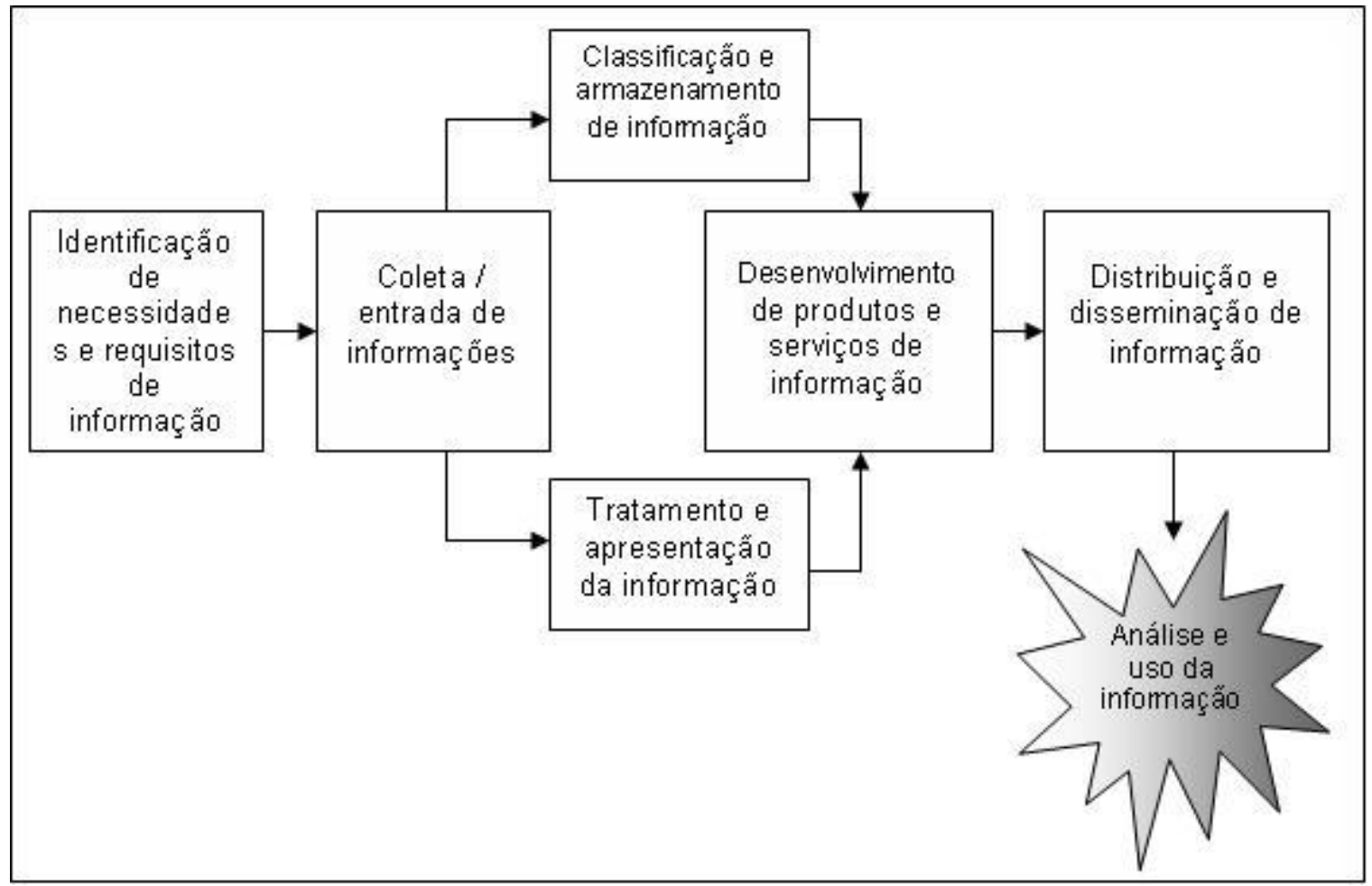

Figura 4 - Tarefas do processo de gerenciamento de informação.

Fonte - McGee; Prusak (1994)

A segunda tarefa do processo é denominada classificação/armazenamento e tratamento/apresentação de informação. Na realidade são duas tarefas condensadas em uma única. Na terceira tarefa, entendida por desenvolvimento de produtos e serviços de informação ocorre a possibilidade do usuário contribuir para o processo. McGee e Prusak (1994, p. 119) salientam "é geralmente nessa tarefa que os usuários finais do sistema podem aproveitar seu próprio conhecimento e experiências para trazer notáveis perspectivas ao processo".

A última tarefa do processo de gerenciamento de informação de McGee e Prusak é intitulada de distribuição e disseminação da informação. Para os autores (1994, p. 124) "ao dedicar-se a essa tarefa, os profissionais que se integrarem ao processo com um entendimento rico e profundo das necessidades de informação de indivíduos-chave, divisões, ou mesmo em toda a empresa, incorporam a ele um valor substancial".

Finalizando as etapas de gerenciamento de informação, McGee e Prusak (1994) ressaltam que diversas organizações que investiram em informação fracassaram, pois, os gestores da informação ${ }^{1}$ não estavam conscientes de suas funções, ou ainda, o gerenciamento da informação não era tido como de valor estratégico pelo restante da organização.

\footnotetext{
${ }^{1}$ Pessoas responsáveis pelo gerenciamento da informação na organização.
} 
Seguidamente, contextualiza-se o modelo de Beal (2004). Neste modelo (figura 5) a autora apresenta sete etapas que representam o fluxo da informação nas organizações. A primeira etapa do modelo de Beal (2004, p. 30) consiste na identificação das necessidades e requisitos de informação, sendo que este "age como elemento acionador do processo". Beal explicita ainda, que esta etapa é "fundamental para que possam ser desenvolvidos produtos informacionais orientados especificamente para cada grupo e necessidade".

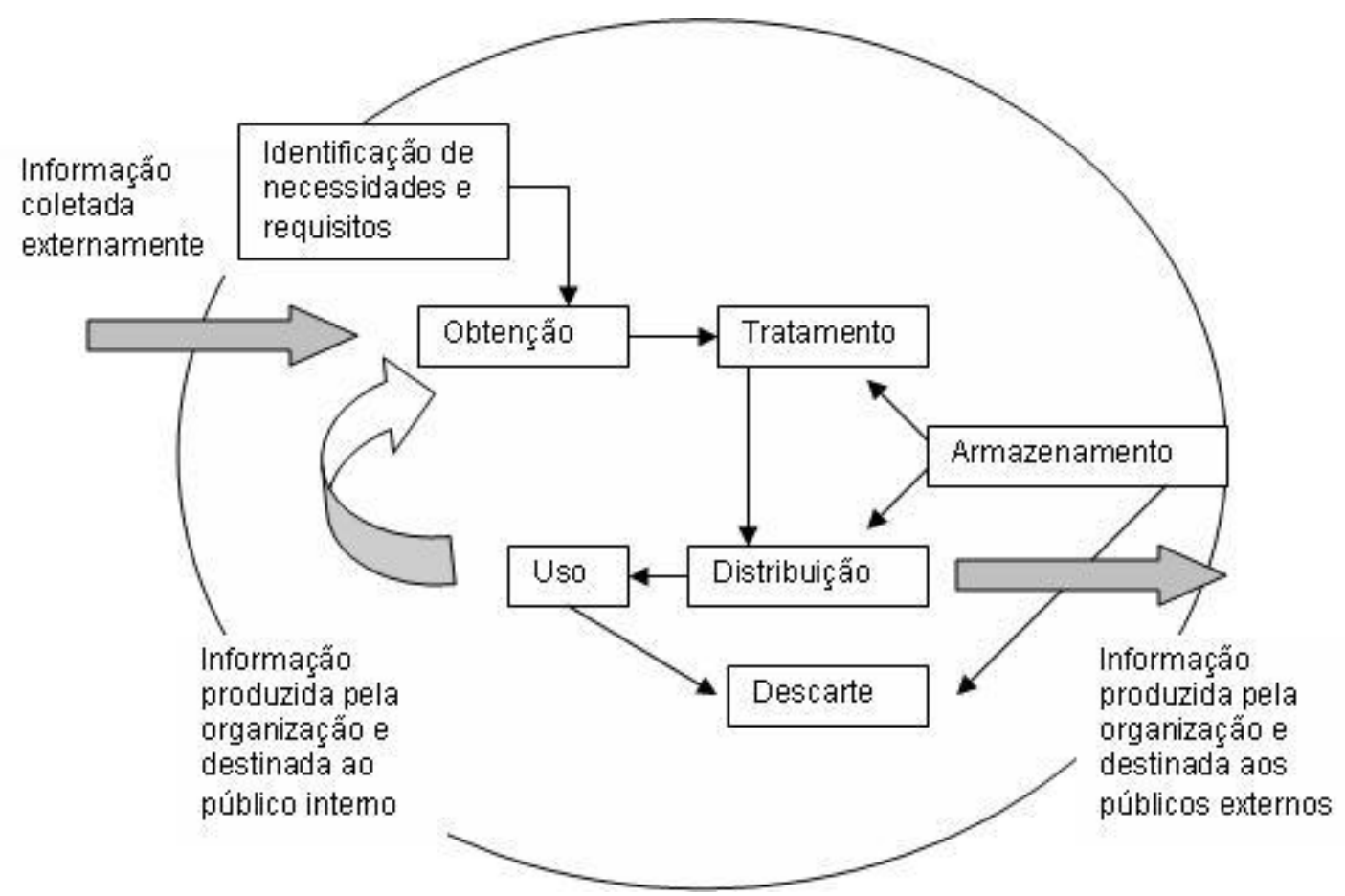

Figura 5 - Modelo de representação do fluxo da informação.

Fonte - Beal (2004)

A segunda etapa diz respeito à obtenção das informações, onde se faz necessária a repetição contínua de alimentação do processo. Beal (2004, p. 30) relata que "na etapa de obtenção da informação são desenvolvidas as atividades de criação, recepção e captura de informação, provenientes de fonte externa ou interna, em qualquer mídia ou formato".

A etapa seguinte do processo de gestão estratégica da informação é denominada de tratamento da informação. Para Beal (2004, p. 30) "antes de estar em condições de ser aproveitada, é comum a informação precisar passar por processos [...] com o propósito de torná-la mais acessível e fácil de localizar pelos usuários".

A quarta etapa consiste na distribuição da informação. Significa dizer que a informação será conduzida ao usuário que dela necessita. Há duas maneiras de distribuir a informação, a primeira interna (usuários da organização) e a segunda externa (fornecedores, clientes, parceiros, etc). O uso da informação compõe a quinta etapa, 
sendo, segundo Beal $(2004$, p. 31) a "[...] mais importante de todo o processo de gestão da informação, embora seja frequentemente ignorada pelas organizações".

Posteriormente, a sexta etapa do processo, denominada armazenamento. Neste momento, de acordo com Beal (2004, p. 31) ocorre a "conservação dos dados e informações, permitindo seu uso e reuso dentro da organização".

A última etapa do modelo de Beal consiste no descarte da informação, significa dizer, que se uma informação se torna obsoleta ou inútil ela deve ser rejeitada. Na visão da autora (2004, p. 32) "excluir dos repositórios de informação corporativos os dados e informações inúteis melhora o processo de gestão da informação [...]". Estas são as sete etapas do processo de gestão estratégica da informação de Beal baseado no fluxo de informação. Desse modo, se visualizou os modelos de gerenciamento da informação que reproduzem com eficiência e significância o processo de gestão da informação baseada nos fluxos informacionais.

O resgate da literatura na área de gestão da informação baseada nos fluxos informacionais permite algumas inferências. A primeira delas é a de que o efetivo gerenciamento da informação em organizações, passa por um processo contínuo de etapas estruturadas, organizadas e sistematizadas (fluxo de informação), pessoas atuantes no processo e responsáveis por tal gestão, além do uso otimizado das fontes de informação.

No que se refere fluxos informacionais, analisando os cinco modelos de gerenciamento da informação é possível constatar que possuem características similares nas fases determinadas. No entanto, Beal (2004), talvez pelo fato de ser o modelo mais recente, é a única autora que insere uma etapa de descarte da informação quando esta se torna inútil. Percebe-se que no modelo de Beal está presente o modelo de Lesca e Almeida, especialmente em relação aos fluxos provenientes do ambiente externo, o ambiente interno e o destinado ao mercado externo.

Após a fundamentação acerca da gestão e os fluxos informacionais, contextualizamse dois estudos derivados de dissertações de mestrado com o intuito de verificar as pesquisas realizadas na temática proposta, embora em ambientes diferenciados.

Mattos (1998) em sua dissertação de mestrado, investigou as informações que dão suporte ao processo decisório e a influência dos grupos que a processam, defendendo que o fluxo de informação faz parte de um processo de construção social do 
conhecimento nas empresas. Sua ausência pode comprometer e prejudicar o desempenho da organização.

Por sua vez, Zegarra (2000) pesquisou o fluxo de informações como suporte à logística em empresas construtoras de edifícios, propondo diretrizes para a elaboração de um modelo de gestão, focado em materiais. A pesquisa foi aplicada em três empresas construtoras de edifícios, realizando entrevistas com membros da direção, responsáveis pela área de suprimentos e engenheiros das obras. A autora fez uma ampla discussão teórica acerca de temas como: gestão de produção, de materiais, de projetos, qualidade, logística e cadeia de suprimentos. Além desses, abordou a informação no interior da organização e posteriormente, a importância da informação no processo de tomada de decisões.

Zegarra (2000, p. 65, grifo nosso) afirma que

Cada indivíduo ou grupo de uma organização precisa da informação de outros indivíduos ou grupos para poder exercer seu trabalho corretamente. A informação suporta o planejamento, controle e a tomada de decisões na organização. A importância de se fornecer oportuna e apropriada é indispensável para tomar uma decisão adequada.

Os resultados do estudo de Zegarra (2000) demonstraram que embora as empresas pesquisadas tivessem seus processos estruturados, ambas, possuíam problemas quanto a informações imprecisas ou incompletas, duplicidade de informações, dificuldade em registrar mudanças ocorridas e em obter informações oportunas. Concluiu afirmando que os fluxos de informação estavam ligados a dois contextos, o macro e o específico. No contexto macro, Zegarra (2000) identificou quatro principais diretrizes e no contexto específico, identificou as características dos principais elementos visando garantir sua eficiência.

Os estudos de Mattos (1998) e Zegarra (2000) vêm reforçar a assertiva de que cada vez mais a informação subsidia a tomada de decisão apropriada em uma organização. Notadamente, no estudo de Zegarra se evidenciam os problemas relacionados ao gerenciamento das informações que mesmo tenho ocorrido em empresas de construção civil podem, a priori, ocorrer nas demais organizações. Assim, é possível afirmar que as organizações devem conceber o gerenciamento da informação visando subsidiar o processo de tomada de decisão.

\section{PROCESSO DE TOMADA DE DECISÕES}


A tomada de decisão será discutida em organizações, ressaltando seus conceitos e inter-relações com a informação, abordando os modelos decisórios. Por fim, contextualiza-se dois estudos sobre o tema.

Cândido; Valentim e Contani (2005, p. 2) afirmam que

[...] as organizações devem gerenciar a informação de forma integrada, a fim de usá-la no momento da tomada de decisão; de que para assegurar sua sobrevivência, crescimento e evolução, uma organização não pode se descuidar da sinergia entre os diferentes setores, bem como do compartilhamento da informação gerada internamente, visando a fluxos dinâmicos e acessíveis; de que é indispensável que sejam utilizadas ferramentas de apoio à gestão estratégica da informação, de modo que possam contribuir para a seleção e filtragem da informação mais adequada à tomada de decisão.

O conceito denota a importância do gerenciamento eficaz da informação para melhorar as decisões a serem tomadas pelas organizações. Nesse sentido, Guimarães e Évora (2004, p. 72) acrescentam que "a maneira como a informação é obtida, organizada, gravada, recuperada e posteriormente utilizada permite ao gerente atuar com mais segurança, aumentando a possibilidade de acerto na tomada de decisão". As autoras não utilizam os termos gestão e fluxo da informação, mas se percebe que estão intrínsecos à sua explanação.

Lesca e Almeida (1994, p. 67) consideram que "a informação é elemento importante na tomada de decisões pertinentes, de melhor qualidade e no momento adequado [...]". As afirmações anteriores culminam no que Cândido, Valentim e Contani (2005, p. 6) resumem

A gestão estratégica da informação é como já se salientou necessária para a manutenção da competitividade organizacional. Por este motivo, torna-se imprescindível o desenvolvimento de estratégias voltadas a ela, de forma que sejam catalisados os fluxos de informação, buscando, entre outras coisas, subsidiar o processo de tomada de decisão.

Contextualizada esta questão, ventila-se a problemática da tomada de decisões. Para tanto, considera-se necessário conceituar tomada de decisão, identificar os tipos de decisão, caracterizar o agente de decisão e, finalmente, mapear os modelos decisórios. Maximiano (2004, p. 111) conceitua a tomada de decisão como

Uma decisão é uma escolha entre alternativas e possibilidades. As decisões são tomadas para resolver problemas ou aproveitar oportunidades. O processo de tomar decisões (ou processo decisório) é a seqüência de etapas que vai da identificação de uma situação que oferece um problema ou oportunidade, até a escolha e colocação em prática de uma ação ou solução.

$\mathrm{Na}$ percepção do autor sobressai a determinação de etapas para a resolução do problema seguindo um processo lógico. Semelhante conceituação adotam Cândido, Valentim e Contani (2005, p. 20) afirmando 
Tomar decisão significa interpretar e agir em relação a uma determinada situação percebida, formulando e/ou apoiando em um ou mais signos que promovam o entendimento do cenário $e$ que gerem uma definição mental do melhor caminho, ou seja, reconhecer o problema e desenvolver a ação.

As afirmações convergem no sentido da resolução de problemas ou situações e, posteriormente, na ação gerada. Diante deste pressuposto, é necessário refletir sobre os principais tipos de decisão nas organizações. Maximiano (2004) aponta dois: (1) as decisões programadas e (2) as não-programadas. As programadas são aquelas decisões tidas como rotineiras pela organização e, as não-programadas são aquelas em que as soluções cotidianas e padronizadas não é passível de resolução.

Chiavenato (1994) indica a hierarquia das decisões no contexto organizacional, elucidando três categorias: decisões estratégicas, decisões táticas e decisões operacionais. As decisões estratégicas, segundo Chiavenato (1994, p. 274) são aquelas que "orientarão as demais decisões tomadas nos níveis intermediário e operacional da empresa dentro de uma hierarquia mais ou menos definida dentro das empresas". Tal hierarquia é ampla e se refere principalmente às decisões que afetam o futuro da organização. Por sua vez, a decisão tática, ou também denominada gerencial, "é o conjunto de tomada deliberada e sistemática de decisões envolvendo empreendimentos mais limitados, prazos mais curtos, áreas menos amplas e níveis mais baixos da hierarquia da organização". (CHIAVENATO, 1994, p. 274). Tal hierarquia, conforme o autor citado é responsável pelo gerenciamento no nível intermediário da organização. Finalmente, as decisões operacionais são aquelas onde é preciso detalhamento das tarefas e operações a serem executadas.

Objetivando caracterizar o 'agente', 'tomador', 'ator', ou ainda 'decisor', entende-se que embora tratados por denominações diferentes, os termos se dirigem para a pessoa (ou grupo) responsável pela tomada de decisão na organização. Os autores Gomes, Gomes e Almeida (2002, p. 15) asseguram que o "decisor (es) influencia (m) no processo de decisão de acordo com o juízo de valor (es) que representa $(m)$ e/ou relações que se estabeleceram". Desse modo, cabe às organizações definirem quem são os agentes do processo de tomada de decisão, visando caracterizá-los e dotá-los de informações pertinentes e no momento necessário.

Maximiano (2004, p. 127) se preocupa em expor que nem sempre é o líder da organização quem toma a decisão, estabelecendo três "possibilidades de participação da equipe nas decisões do líder". Segundo o mesmo autor, as decisões podem ser (1) autocráticas (sem a participação da equipe); (2) compartilhadas (quando o líder divide 
com a equipe as decisões) e (3) delegadas (quando o líder transfere de forma integral as decisões para a equipe).

As possibilidades levantadas irão variar de organização para organização, dependendo, sobretudo, do perfil do seu gestor. Genericamente, autores como Maximiano (2004) Stoner e Freeman (1995) e Rezende (2005) estabelecem etapas para o processo de tomada de decisão, constituindo diversificados modelos.

Os modelos decisórios encontrados na literatura podem ser identificados através de etapas ou fases, de acordo com o entendimento de cada autor, bem como pela denominação dada a cada um deles. Maximiano (2004) denominou de 'processo de resolução de problemas', Stoner e Freeman (1995) 'modelo racional de tomada de decisão' e, finalmente, Rezende (2005) 'modelo decisório convencional' e 'modelo decisório dinâmico'. O primeiro modelo analisado é o de Maximiano (2004), conforme demonstra a figura 6 .

A cada uma das fases evidenciadas na figura, deve-se ter presente que o processo de tomada de decisão surge de uma situação desagradável, desfavorável ou ainda, oportuna e desafiadora. Na primeira fase do processo de tomada de decisão, Maximiano (2004, p. 114) afirma "esta é a fase em que se percebe que o problema está ocorrendo e que é necessário tomar uma decisão".

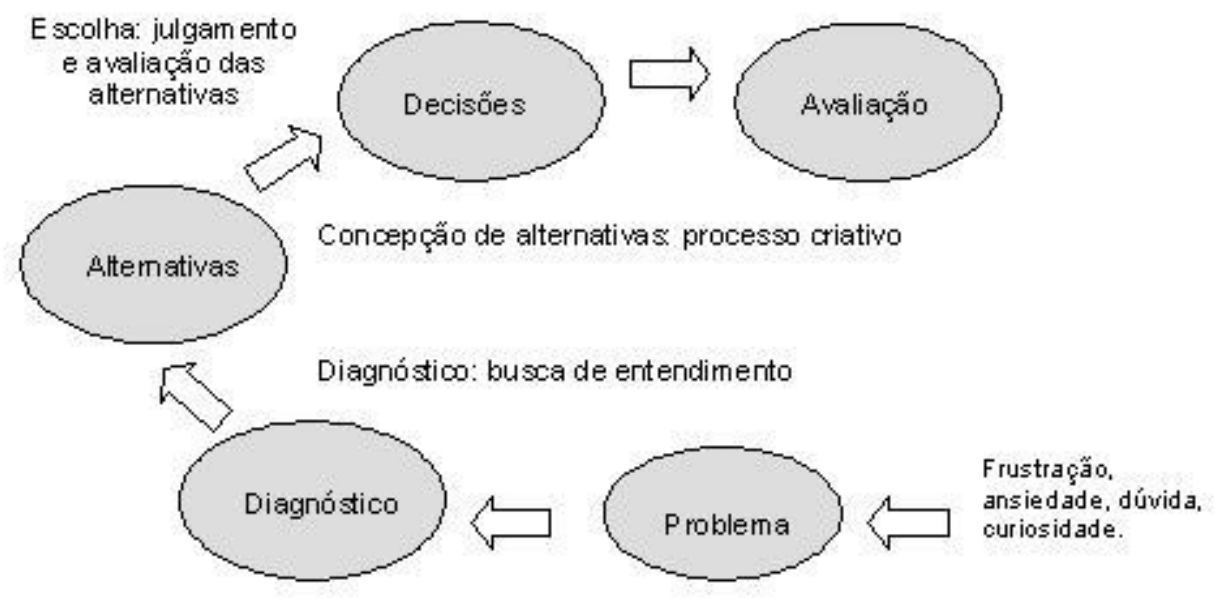

Figura 6 - Modelo decisório

Fonte - Maximiano (2004)

A segunda fase do processo consiste no diagnóstico, ou seja, "procura entender o problema ou oportunidade e identificar suas causas e consequências" (MAXIMIANO, 2004 , p. 114). A geração de alternativas aparece como terceira fase do processo de tomada de decisão. Nessa fase, o autor (2004, p. 117) observa que "muitas vezes, as 
alternativas já vêm junto com o problema ou oportunidade. Em outros casos, não há alternativas prévias e é preciso ter idéias". A principal técnica utilizada é a de brainstorming (tempestade de idéias). A quarta fase do processo de tomada de decisão consiste na escolha de uma alternativa. Nesse momento, de acordo com Maximiano (2004, p. 119) "[...] as alternativas são avaliadas, julgadas e comparadas, para que uma escolha possa ser feita". Ao findar o modelo de Maximiano (2004), tem-se a percepção de que o elemento humano é fator chave nesse processo. Observa-se que não há retroalimentação ou feedback no processo e ainda, que a ação não está explícita ao modelo.

O segundo modelo analisado é o de Stoner e Freeman (1995), denominado modelo racional de tomada de decisão (figura 7). Composto por quatro estágios este modelo é o mais conhecido no processo de tomada de decisão.

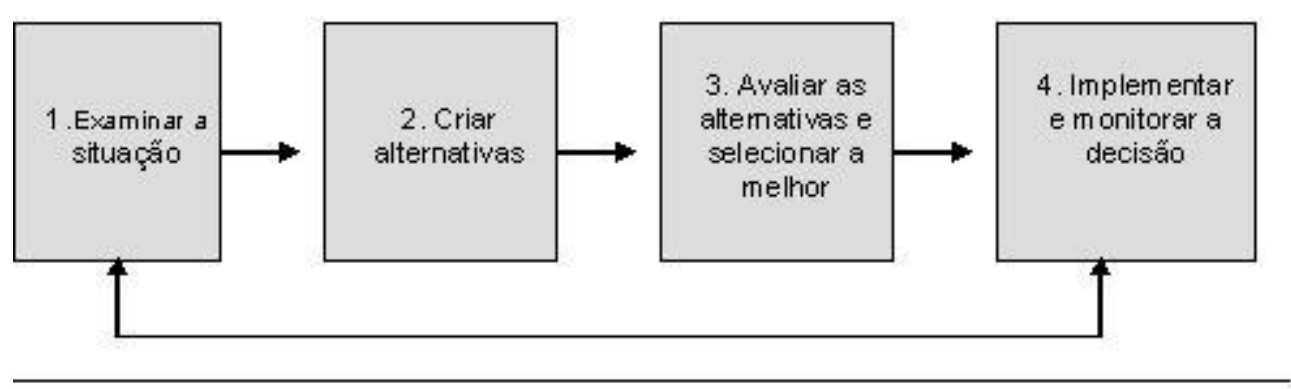

Figura 7 - Modelo racional de tomada de decisão

Fonte - Stoner e Freeman (1995)

O primeiro estágio do processo racional defendido por Stoner e Freeman (1995) consiste em examinar a situação através de três aspectos: (1) definir o problema; (2) identificar os objetivos da decisão e (3) diagnosticar as causas.

No segundo estágio é necessário criar alternativas viáveis e múltiplas, antes de tomar a decisão. Os autores (1995, p. 186) afirmam que "este estágio pode ser razoavelmente simples para a maioria das decisões programadas, mas não tão simples para as decisões complexas, especialmente se há limites de tempo". Nesse estágio a aplicação da técnica de brainstorming é recomendável para que surjam novas alternativas.

O próximo estágio requer a avaliação das alternativas e seleção da melhor. Os autores (1995) sugerem que os decisores façam questionamentos acerca da exeqüibilidade da alternativa; da satisfação que a alternativa trará e suas conseqüências para a organização. Nesse, Stoner e Freeman apresentam a árvore da decisão como ferramenta de avaliação das alternativas. 
O último estágio do processo diz respeito à implementação e monitoramento da decisão. Para os autores (1995, p. 187) "implementar uma decisão envolve mais do que dar as ordens adequadas. Os recursos devem ser conseguidos e alocados de acordo com a necessidade". O monitoramento da decisão vem em seguida, onde se observa fatores internos e externos à organização. O modelo de Stoner e Freeman (1995) é até certo ponto de fácil assimilação e aplicação para as decisões programadas, embora não totalmente ajustada quanto às decisões não-programadas e complexas.

Rezende (2005, p. 45) apresenta dois modelos de tomada de decisão estabelecendo que

Os modelos decisórios nas organizações contribuem para os processos de tomada de decisões, principalmente de ordem tática e estratégica. Eles são adequados às situações e às peculiaridades de cada organização, buscando fornecer as informações e conhecimentos efetivos e inteligentes.

O primeiro modelo apresentado pelo autor é o modelo decisório convencional ou também denominado modelo mental trivial (figura 8). O autor (2005, p. 45) salienta que nesse modelo os "dados são transformados em informações e conseqüentemente em conhecimentos". Seguidamente, é plausível que os agentes tomem as decisões e ações imperativas. E adiciona "as ações executadas pelos decisores ou gestores geram resultados, sejam positivos ou negativos, retroalimentando o ciclo decisório". (REZENDE, 2005, p. 46).

Ainda sobre o modelo convencional de Rezende (2005) é importante destacar que sua aplicabilidade se dá em ambientes e situações rotineiras, que não exijam análises profundas. Observa-se também que o processo de transformar informação em conhecimento é complexo e exige tempo e dedicação do agente.

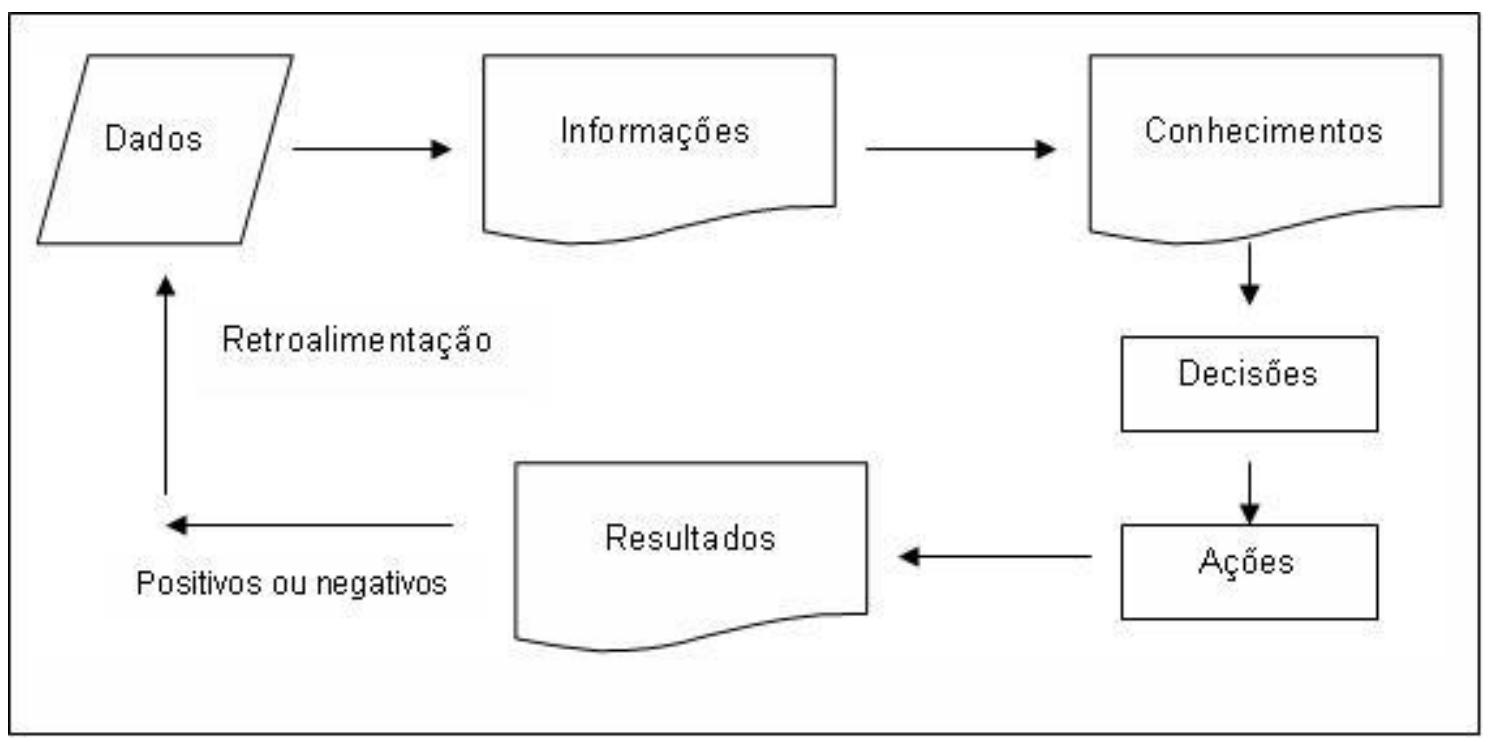


Figura 8 - Modelo decisório convencional

Fonte - Rezende (2005)

O segundo modelo proposto por Rezende (2005) é chamado de modelo decisório dinâmico, conforme a figura 9 .

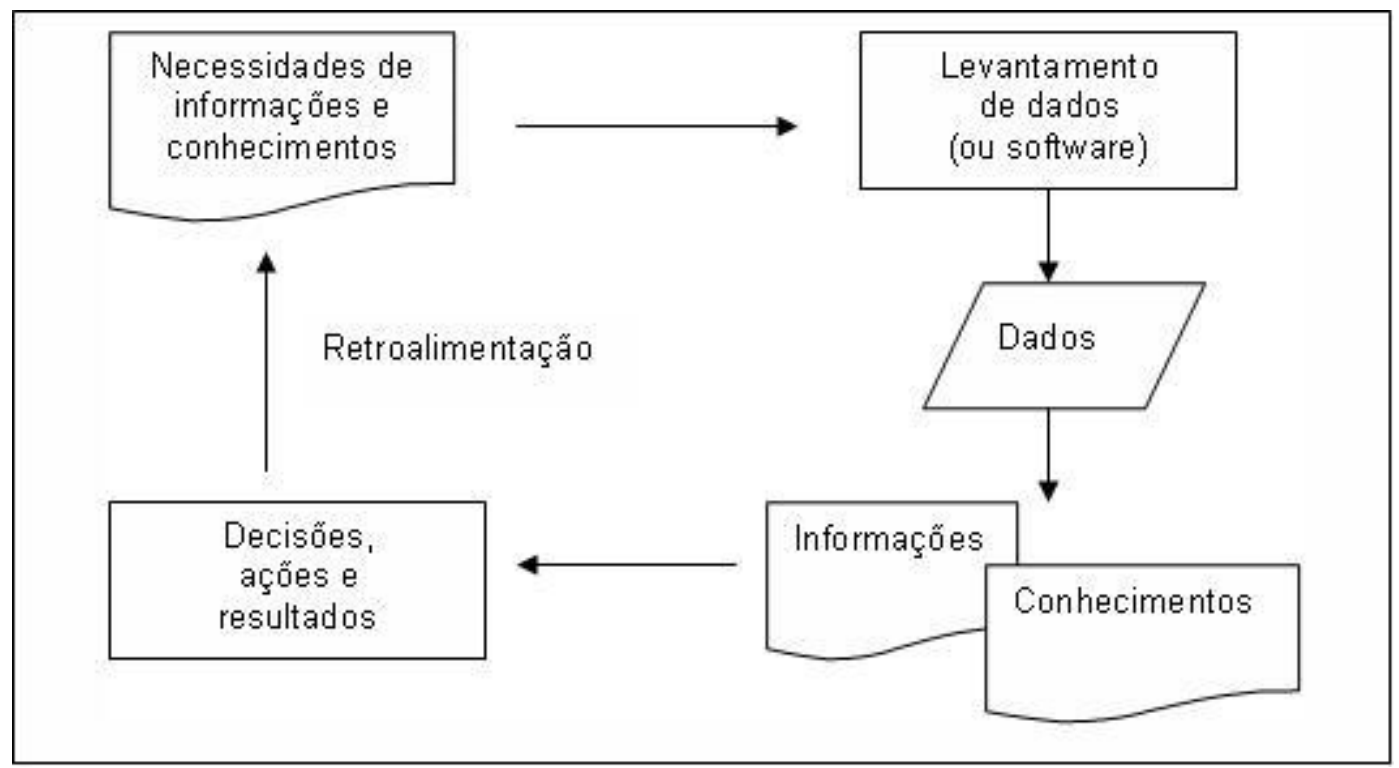

Figura 9 - Modelo decisório dinâmico

Fonte - Rezende (2005)

Neste modelo, Rezende (2005, p. 48) assegura que "as necessidades de informação devem ser modeladas a partir das exigências dos decisores e gestores da organização". Além disso, o mesmo autor (2005, p. 47) esclarece "o destaque nesse modelo é a necessidade de informação e não o tratamento de dados". Impõe-se a esse modelo o desafio de sistematizar as informações a serem utilizadas na organização. Constata-se que o modelo decisório dinâmico representa uma boa alternativa de gerenciamento para organizações de caráter público ou privado, uma vez que se faz necessária a identificação das informações. No entanto, ressalta-se que o autor parece utilizar a informação e o conhecimento como sinônimos, de maneira equivocada. No processo de tomada de decisão, especialmente os modelos apresentados, possuem etapas semelhantes, havendo sutis modificações entre eles.

Crê-se que a efetivação prática, tanto das etapas dos fluxos de informação quanto do processo de tomada de decisão, só poderá ser comprovada na medida em que forem testados à realidade das organizações. Mesmo assim, considera-se que os modelos apresentados simulam genericamente a gestão diária das organizações.

A seguir, apresentam-se duas pesquisas em nível de dissertação de mestrado que abordam a problemática da tomada de decisão, das quais os fluxos informacionais são tidos como suporte. 
Pletsch (2003) estudou o fluxo de informações para a tomada de decisão em uma empresa de telecomunicações. Para tanto, abordou a questão da informação como elemento indispensável ao processo de tomada de decisões. Baseada nos resultados obtidos, a autora propôs um fluxo de informações estruturado para a empresa estudada. As principais considerações tecidas denotam que as informações inicialmente geradas não chegam ao destino final, não havendo retroalimentação no processo. Outra constatação é a de que o funcionário não percebe a importância do trabalho desenvolvido. No entanto, a pesquisa não demonstrou os resultados acerca da análise do fluxo de informações para a tomada de decisões.

Por sua vez, Dantas (2005) pesquisou sobre a gestão da informação na tomada de decisão em uma instituição financeira brasileira orientada para o cliente. Para ela (2005, p. 24-25, grifo nosso)

No setor de serviços, a informação se constitui a base da competição. No entanto, é preciso que os executivos de nível estratégico definam corretamente o papel da informação na empresa, para integrar a definição à execução das ações estratégicas. A informação de qualquer natureza (científica, econômica, social, técnica, gerencial) é considerada como insumo básico do atual cenário competitivo. Como a informação tem papel de suporte aos tomadores de decisão, é importante que cada segmento de mercado direcione seus esforços para a captura, a armazenagem e a utilização da informação correta.

Outro ponto que chamou a atenção foi a preocupação dos entrevistados com a qualidade das informações que buscam e utilizam. Dantas (2005, p. 113-114) esclarece que

Como a tomada de decisão depende das informações, é importante que estas sejam revestidas de qualidade. Não basta ter apenas informações é necessário tê-las com qualidade para que o processo decisório seja bem sucedido.

Desse modo, infere-se que a gestão da informação, representa aspectos importantes e essenciais para a sustentabilidade das organizações. Acrescente-se a essa assertiva que as organizações que desejarem se manter competitivas e no mercado, precisam estar atentas para o fato de que a informação gerenciada eficazmente, dentro das etapas determinadas, poderá suportar a tomada de decisões. Com o suporte adequado subsidiado pelos fluxos de informações a qualidade das decisões tende a ser potencializada, obtendo-se os resultados pretendidos.

\section{CONSIDERAÇÕES FINAIS}

A informação desempenha papel importante em todos os setores econômicos, como elemento propulsor do conhecimento e inovação, exigindo gerenciamento eficaz e 
esforços conjuntos. A investigação do fluxo informacional permite verificar e subsidiar o processo de tomada de decisões. Por meio do mapeamento dos fluxos, torna-se possível reconhecer as etapas pelas quais as informações perpassam e verificar quais os aspectos falhos do processo. É preciso conhecer as necessidades de uso e usuários da informação para mapear as fontes de informação pertinentes ao contexto. A partir da análise dos modelos de fluxos de informação e dos processos de tomada de decisão é possível verificar que apresentam poucas diferenças, apesar de advirem de contextos heterogêneos. Smit e Barreto (2002) fazem uma proposição diferenciada, a apropriação da informação pelo indivíduo, que resultaria, ou não, em resultados para a organização. É um questionamento importante e de difícil mensuração, que merece atenção das pesquisas na área. Os modelos de tomada de decisão apontam para uma racionalidade desejada, mas nem sempre possível nas tramas dos relacionamentos humanos dentro de uma organização. Salienta-se que os contextos de desenvolvimento precisam ser levados em consideração, já que interferem diretamente na percepção e condução dos processos. Por fim, esse trabalho teve o intuito de fornecer uma contribuição ao processo de gestão da informação através da apresentação de modelos de fluxos que precisam ser mapeados e compreendidos nas organizações, afim de que o processo de tomada de decisão seja qualificado.

\section{REFERÊNCIAS}

BARRETO, A. A. Os destinos da ciência da informação: entre o cristal e a chama. DataGramaZero: Revista de Ciência da Informação, Rio de Janeiro, n. 0, dez. 1999. Disponível em: <www.http://www.dgz.org.br/dez99/F_I_aut.htm>. Acesso em: 11 abr. 2010.

BEAL, A. Gestão estratégica da informação. São Paulo: Atlas, 2004.

CÂNDIDO, C. A; VALENTIM, M. L; CONTANI, M. L. Gestão estratégica da informação: semiótica aplicada ao processo de tomada de decisão. DataGramaZero: Revista de Ciência da Informação, Rio de Janeiro, v. 6, n. 3, jun. 2005. Disponível em: <http://www.dgz.org.br/jun05/F_I_art.htm>. Acesso em: 22 jul. 2010.

CASTELLS, M. O espaço de fluxos. In: Janeiro: Paz e Terra, 2001. v. 1. Cap. 6. p. 467-521.

CHIAVENATO, I. Administração de empresas. 3. ed. São Paulo: Makron Books, 1994.

DANTAS, M. C. B. A gestão da informação na tomada de decisão em uma instituição financeira brasileira orientada para o cliente. 2005. 137 f. Dissertação (Mestrado em Ciência da Informação). Universidade de Brasília, Brasília, 2005. 
DAVENPORT, T. H. Ecologia da informação. São Paulo: Futura, 1998.

GOMES, L. F. A. M.; GOMES, C. F. S.; ALMEIDA, A. T. Tomada de decisão gerencial. São Paulo: Atlas, 2002.

GUIMARÃES, E. M. P.; ÉVORA, Y. D. M. Sistema de informação: instrumento para tomada de decisão no exercício da gerência. Ciência da Informação, Brasília, v. 33, n. 1, p. 72-80, jan./abr. 2004.

LESCA, H.; ALMEIDA, F. C. Administração estratégica da informação. Revista de Administração, São Paulo, v. 29, n. 3, p. 66-75, jul./set. 1994.

MATTOS, M. C. As informações que dão suporte ao processo decisório e a influência dos grupos que a processam. Belo Horizonte, 1998. 141 f. Dissertação (Mestrado em Ciência da Informação). Universidade Federal de Minas Gerais, Belo Horizonte, 1998.

MAXIMIANO, A. C. A. Introdução à administração. 6. ed. São Paulo: Atlas, 2004.

MCGEE, J.; PRUSAK, L. Gerenciamento estratégico da informação. Rio de Janeiro: Campus, 1994.

OLIVEIRA, M.; BERTUCCI, M. G. E. S. A pequena e média empresa e a gestão da informação. Informação \& Sociedade: Estudos, João Pessoa, v. 13, n. 2, 2003. Disponível em: <www.informacaoesociedade.ufpb.br/pdf/is1320303.pdf>. Acesso em: 30 ago. 2009.

PLETSCH, E. O fluxo de informações como apoio à tomada de decisão: o caso da Central de Atendimento da Telet S/A. 2003. 105 f. Dissertação (Mestrado em Administração). Universidade Federal do Rio Grande do Sul, Porto Alegre, 2003.

REZENDE, D. A. Sistemas de informações organizacionais. São Paulo: Atlas, 2005.

SMIT, J. W.; BARRETO, A. A. Ciência da Informação: base conceitual para a formação do profissional. In: VALENTIM, M.L. (Org.). Formação do profissional da informação. São Paulo: Polis, 2002. Cap.1. p. 9-23.

STONER, J. A. F.; FREEMAN, R. E. Administração. 5. ed. Rio de Janeiro: Prentice Hall do Brasil, 1995.

ZEGARRA, S. L. V. Diretrizes para a elaboração de um modelo de gestão de fluxos de informações como suporte à logística em empresas construtoras de edifícios. 2000. $214 \mathrm{f}$. Dissertação (Mestrado em Engenharia de Construção Civil). Universidade de São Paulo, São Paulo, 2000.

\section{Title}

Managing the information flow to support the process of decision making: a review

\section{Abstract}

It aims to map the information flow models in the process of making decisions regarding which information has an important and essential role in organizations, requiring effective management is 
important to establish systematized and structured processes, steps or flows by people that are responsible for obtaining the desired results. The research about information flow allows to verify and to support the process of decision making. This paper contributes to understand the basic function of information in supporting decision-making so to allow increasing quality, uncertainties reduction and its necessary management.

\section{Keywords}

Information flow. Decision making. Information management.

\section{Título}

Gestión del flujo de información como apoyo en el proceso de toma de decisiones: una revisión

\section{Resumen}

Objectiva mapear los modelos de flujo de información en el proceso de toma de decisiones considerando que la información, por tener un papel importante y esencial en las organizaciones, requieren una gestión eficaz y los esfuerzos conjuntos de sus miembros. Destaca como esencial a la gestión de la información el establecimiento de procedimientos, etapas o flujos sistematizados y estructurados, asociados a las personas responsables por su conducción, para que alcancen los resultados deseados. Refuerza que la investigación del flujo informacional posibilita verificar y apoyar el proceso de toma de decisiones. Se espera, con este trabajo, ayudar en la comprensión de que la información ejerce función básica para el apoyo a la toma de decisiones en términos de aumento de la calidad y reducción de incertidumbres.

\section{Palabras clave}

Flujo de información. Toma de decisiones. Gestión de la información.

Recebido em: 06.07.2010

Aceito em: 15.09 .2010 